\title{
Joint Incidence of Asthma and Rhinitis in Macedonia
}

\author{
M. Zdraveska ${ }^{*}, 1$, D. Dimitrievska ${ }^{1}$, D. Todevski ${ }^{1}$, A. Gjorcev ${ }^{1}$, E. Janeva ${ }^{1}$, \\ I. Pavlovska ${ }^{2}$ and B. Zafirova-Ivanovska ${ }^{2}$
}

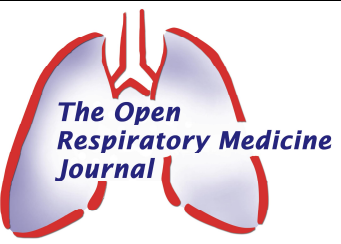

\author{
${ }^{1}$ Pulmology and Allergy Clinic Skopje, Macedonia, ${ }^{2}$ Institute of Epidemiology and Biostatistics with Medical \\ Informatics, Medical Faculty, Skopje, Macedonia
}

\begin{abstract}
The concept of "united airways disease", based on many similar features and mutual interactions in the pathogenesis of asthma (A) and rhinitis (R), has led to an integral approach to their management. We conducted this study to determine the quantity of the problem of joint incidence of $\mathrm{A}$ and $\mathrm{R}$ in $\mathrm{R}$. Macedonia, and, perhaps to obtain information on a potential causative effect of the two diseases.

Three hundred eighty six patients, who presented with wheezing and/or upper respiratory symptoms at the Pulmology and Allergy Clinic, Skopje, were included during a period of 48 months. The presence of bronchial hyperreactivity - BHR (positive histamine challenge), atopy (prick test to seasonal or perennial inhaled allergens), rhinitis symptoms (such as nasal secretion and obstruction) and $\mathrm{X}$-ray of paranasal sinuses was registered by a specially designed questionnaire. $\mathrm{R}$ was diagnosed in 106 of the subjects (27.5\%), and A in 280 (72.5\%). Among the patients with A, co-incidence with $\mathrm{R}$ was found in $219(76.5 \%)$. Including X-ray of paranasal sinuses to the diagnostic protocol increased this percentage to over 90\% (256 patients). From the 219 patients with A and R together, 127 (57.99\%) had positive atopy. On the other hand, 19 $(18.0 \%)$ of the rhinitis-only patients had positive BHR without asthma symptoms. The follow up of the rhinitis patients with positive BHR revealed 4 patiets who developed asthma within 36 months, but this was also the case with 2 of the subjects with $\mathrm{R}$ and negative BHR. In conclusion, the co-incidence of $\mathrm{A}$ and $\mathrm{R}$ in our material is $78.21 \%$, or $91.4 \%$ (including sinusitis); a greater co-existence of $\mathrm{A}$ and $\mathrm{R}$ is found in atopic patients. The patients with allergic $\mathrm{R}$ are at high risk for developing A and should be monitored in the future and the $\mathrm{R}$ symptoms should be adequately treated in order to minimize the risk for developing asthma.
\end{abstract}

Keywords: Asthma, rhinitis, epidemiology, united airways, joint incidence.

\section{INTRODUCTION}

Allergic diseases such as asthma, rhinitis, conjunctivitis, urticaria-angioedema, and atopic dermatitis share a high and increasing prevalence throughout the world. Affecting between 25 and $50 \%$ of the population, they impair the health and the quality of life of the subjects, causing a global financial and social burden to individuals and societies. The substantial progress that has been achieved in the knowledge of the mechanisms underlying allergic diseases shows that they share multiple pathophysiologic similarities and might be various phenotypic expressions of a process, systemic in nature, therefore requiring a global diagnostic, as well as therapeutic approach to the allergic patient [1-3].

The co-existence of asthma and rhinitis is documented in numerous epidemiological studies. Both entities share similar epidemiologic parameters (such as increasing prevalence, especially in developed countries), common histological and functional characteristics as well as pathophysiologic mechanisms. The common airway is triggered by similar agents and the impact of the upper on the lower airways is documented in numerous studies [4-6].

*Address correspondence to this author at the Bul. Partizanski odredi 149 153, 1000 Skopje, Macedonia; Tel: +389 71 400765;

Fax:+389 2 3211468; E-mail: mzdraveska@gmail.com
The joint incidence of rhinitis and asthma and their mutual influence has been noted since ancient times, as Galenus recommended "purging nostrils of secretions to relieve the lungs". The link between hay fever and asthma was described in the late nineteenth century by Bostok and Blakely, and Rackeman (1920) found that "lesions of the nose lead to development of asthma". In the past decades, genetic research provided scientific basis of these observations, and numerous studies lead to publishing guidelines and recommendations such as the Global initiative for asthma (GINA) and the Allergic Rhinitis and its impact on Asthma (ARIA) [7, 8], which recognize the interactions between these two entities and support a global therapeutic and diagnostic approach to allergic patients. The need of a wider perspective to allergic patients is also emphasized by the numerous epidemiologic studies which confirm that rhinitis precedes asthma in $6-20 \%$ of cases. Verdiani refers that perennial rhinitis is associated with greater risk for development of airway hyperresponsivenes, and in a 14-yers follow up study, Johnstone found that $50 \%$ of children with allergic rhinitis develop asthma in the following 3-4 years [9].

In spite the contemporary recommendations, both asthma and rhinitis are still highly sub-diagnosed and seldom treated simultaneously, especially in Macedonia, where the treatment of allergic diseases is separated on the basis of 
shock organs; thus patients are distributed to either dermatologists, respiratory or ear, nose and throat (ENT) specialists, depending on their dominant complaint. This approach usually leads to treating one allergic manifestation, often without even recognizing the existence of symptoms deriving from other shock organs. The translation of the GINA and ARIA guidelines in Macedonia, as well as publishing the National guidelines for treatment of asthma in 1996 [10], imposed the need of recognizing the problem of joint incidence of asthma and rhinitis and developing a protocol for a global diagnostic approach to the patients.

\section{OBJECTIVE}

To determine the joint incidence of asthma and rhinitis in our population, the influence of atopy on the incidence of asthma, rhinitis, the coexistence of both, and the importance of positive BHR in the development of asthma in atopic and nonatopic patients with rhinitis.

\section{MATERIALS AND METHODS}

In order to determine the joint incidence of asthma and rhinitis in our population, we designed a prospective study, conducted at the National Center for Asthma and COPD at the Pulmology and Allergy Clinic in Skopje, in the period of 48 months. All patients who consulted the outpatient service of the Clinic with either symptoms of asthma, rhinitis, or both were eligible and were designated to a predefined diagnostic protocol. A total of 386 patients were enrolled in the study and followed the following protocol:

1. General data and basic demographic features were collected from all of the patients.

2. The diagnostic protocol for asthma followed the GINA recommendations (clinical presentation, standard reversibility test with $400 \mathrm{mcg}$ of salbutamol. Broncho-provocation test with metacholine was performed in patients where asthma could not be confirmed with reversibility test, subjects with rhinitis symptoms only, or subjects with normal lung function at initial evaluation.

3. Presence of atopy was documented with standard skin prick tests to seasonal and perennial allergens.

4. Rhinitis was diagnosed with the presence of symptoms such as sneezing, rhinorhea, obstruction. Detection of sinusitis was included by registering the presence of post-nasal drip and adding routine X-ray for paranasal sinuses to the protocol.

Patients with rhinitis/rhinosinusitis alone were additionally followed for the period of duration of the study by follow up visits every 6 moths, actively looking for incidence of symptoms or lung function parameters for newly developed asthma.

\section{Statistical Methods}

Program Statistica for Windows was used for statistical data workup. Categorical variables were showed by absolute and relative numbers, while numerical series were analyzed with measures of central tendency as well as with measures of dispersion. Probable existence of association, i.e. significance determination in the analyzed difference among separate statistical series was tested by Pearson's $\chi^{2}$ test.

The risk factors were quantified through calculation of risks with Odds ratio (OR), having a role in occurrence of the disease, and with the Confidence intervals (CI - 95\%), the statistical significance at error level less than $0.05(\mathrm{p})$ was defined.

\section{RESULTS}

The characteristics of the patients enrolled in the study are shown Table $\mathbf{1}$.

Table 1. Characteristics of the patients.

\begin{tabular}{|c|c|c|}
\hline Variables & Number (N) & $\%$ \\
\hline Patients No & \multicolumn{2}{|c|}{386} \\
\hline \multicolumn{3}{|l|}{ Gender } \\
\hline Female gender & 214 & 55.4 \\
\hline Male gender & 172 & 44.6 \\
\hline \multicolumn{3}{|l|}{ Age $(y r)$} \\
\hline $16-20$ & 48 & 12.4 \\
\hline $21-30$ & 88 & 22.8 \\
\hline $31-40$ & 91 & 23.6 \\
\hline$>41$ & 159 & 41.2 \\
\hline Age (average) & \multicolumn{2}{|c|}{$37.7 \pm 13.4$} \\
\hline \multicolumn{3}{|l|}{ Asthma diagnosis } \\
\hline With athma & 280 & 72.5 \\
\hline Without athma (Rhinitis only) & 106 & 27.5 \\
\hline \multicolumn{3}{|l|}{ Rhinitis } \\
\hline With rhinitis & 325 & 84.2 \\
\hline Without rhinitis & 61 & 15.8 \\
\hline \multicolumn{3}{|l|}{$X$-ray of paranasal sinuses } \\
\hline Positive for rhinosinusitis & 302 & 78.2 \\
\hline Negative for rhinosinusitis & 84 & 21.8 \\
\hline \multicolumn{3}{|l|}{ Atopic status } \\
\hline Positive seasonal allergens & 109 & 28.2 \\
\hline Positive perenial allergens & 72 & 18.6 \\
\hline Positive seasonal and perenial allergens & 55 & 14.2 \\
\hline No atopy detected & 105 & 39.0 \\
\hline Atopic status in asthma-only patients & 61 & \\
\hline Positive seasonal allergens & 6 & 9.8 \\
\hline Positive perenial allergens & 6 & 9.8 \\
\hline Positive seasonal and perenial allergens & 1 & 1.6 \\
\hline No atopy detected & 48 & 78.6 \\
\hline Subgroup- asthma patients & \multicolumn{2}{|c|}{280} \\
\hline Asthma and Rhinitis-coexistence & 219 & 76.5 \\
\hline Asthma and Rhinosinusitis (X-ray) & 256 & 91,4 \\
\hline Asthma without rhinitis & 61 & 21.7 \\
\hline Asthma without rhinosinusitis & 24 & 8.6 \\
\hline
\end{tabular}


Table 2. Prevalence of bronchial hyperresponsiveness (BHR).

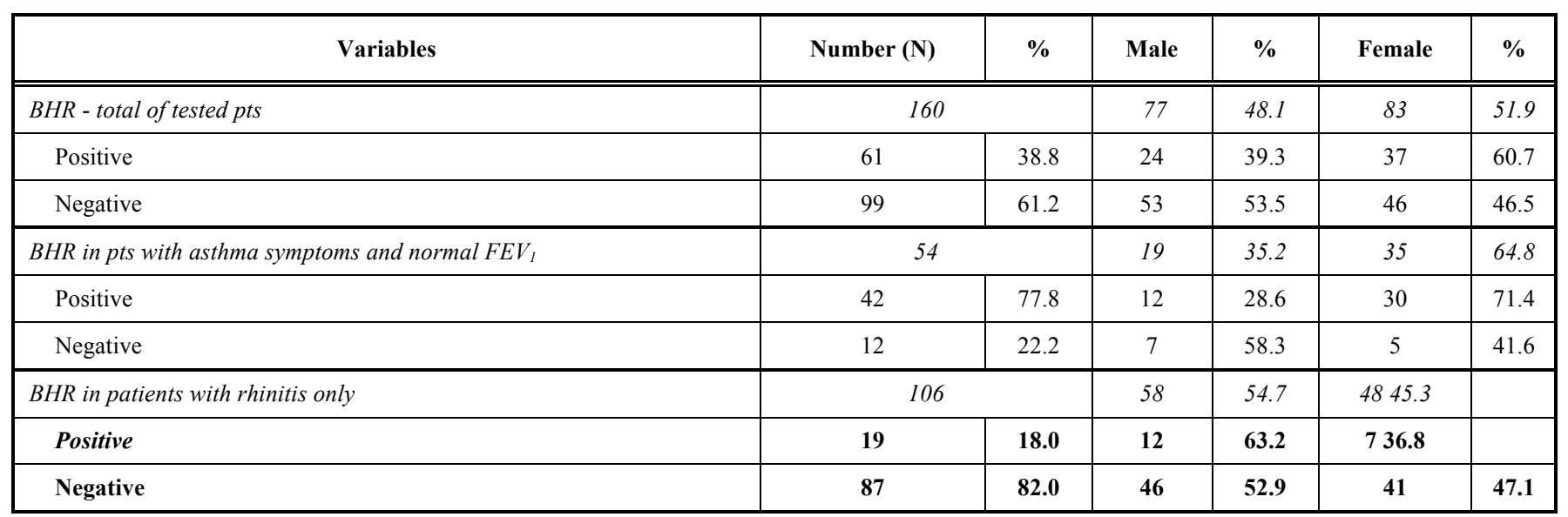

The presence of bronchial hyperresponsiveness was tested in a total of 160 patients, 54 with asthma symptoms and normal $\mathrm{FEV}_{1}$ and 106 with rhinitis-only (Table 2).

Univariant analysis for the presence of atopy, asthma and rhinitis was done, in order to determine their role as risk factors in the whole tested sample. The results show that the presence of atopy as well as rhinitis is a significant risk factor for bronchial asthma, independent of gender (OR 0.11; $\chi^{2}=49.9, p=0.000$ and OR $\left.0.01 ; \chi^{2}=26.5, p=0.000\right)$. Atopy also proved to be an independent risk factor for the presence of rhinitis (OR 7.23; $\chi^{2}=44.5, \mathrm{p}=0.000$ ). Analyzing the subgroup of asthma-only patients and its comparison to the $\mathrm{A}+\mathrm{R}$ group showed that the presence of atopy is a significant risk factor for developing coexistence of asthma and rhinitis, but not asthma alone. In the subgroup of asthmatic with no signs of rhinitis, atopy was not detected in $78 \%$, and the probability not to be atopic in this subgroup of patients was significantly higher (OR 3.745; 95\% CI 1.947.22, $\mathrm{p}=0.0001$ ) (Tables 3-5).

Table 3. Estimation of the risk to have asthma depending on the presence of atopy.

\begin{tabular}{|c|c|c|c|c|}
\hline Variables & With Asthma ${ }^{1}$ & Without asthma $^{2}$ & $\mathbf{O R}^{3}$ & $95 \% \mathrm{CI}^{4}$ \\
\hline \multicolumn{5}{|c|}{ Atopy (in all subjects) } \\
\hline Positive & 141 & 95 & 0.11 & \multirow[t]{2}{*}{$0.06-0.23$} \\
\hline Negative & 139 & 11 & 1.00 & \\
\hline \multicolumn{5}{|c|}{$\chi^{2}=49.9(\mathrm{p}=0.000)$} \\
\hline \multicolumn{5}{|c|}{ Atopy (male subjects) } \\
\hline Positive & 59 & 54 & 0.08 & \multirow[t]{2}{*}{$0.03-0.23$} \\
\hline Negative & 55 & 4 & 1.00 & \\
\hline \multicolumn{5}{|c|}{$\chi^{2}=27.3(\mathrm{p}=0.000)$} \\
\hline \multicolumn{5}{|c|}{ Atopy (female subjects) } \\
\hline Positive & 82 & 41 & 0.17 & $0.07-0.39$ \\
\hline Negative & 84 & 7 & 1.00 & \\
\hline \multicolumn{5}{|c|}{$\mathrm{X}^{2}=19.8(\mathrm{p}=0.000)$} \\
\hline
\end{tabular}

Table 4. Estimation of the risk to have asthma depending on the presence of rhinitis.

\begin{tabular}{|c|c|c|c|c|}
\hline Variables & With Asthma ${ }^{1}$ & Without Asthma $^{2}$ & $\mathrm{OR}^{3}$ & $95 \% \mathrm{CI}^{4}$ \\
\hline \multicolumn{5}{|c|}{ Rhinitis (in all subjects) } \\
\hline Positive & 219 & 106 & 0.01 & \multirow[t]{2}{*}{$0.001-0.273$} \\
\hline Negative & 61 & 0.5 & 1.00 & \\
\hline \multicolumn{5}{|c|}{$\chi^{2}=26.5(p=0.000)$} \\
\hline \multicolumn{5}{|c|}{ Rhinitis (male subjects) } \\
\hline Positive & 96 & 58 & 0.04 & \multirow[t]{2}{*}{$0.002-0.753$} \\
\hline Negative & 18 & 0.5 & 1.00 & \\
\hline \multicolumn{5}{|c|}{$\chi^{2}=7.8(p=0.000)$} \\
\hline \multicolumn{5}{|c|}{ Rhinitis (female subjects) } \\
\hline Positive & 123 & 48 & 0.03 & \multirow[t]{2}{*}{$0.001-0.484$} \\
\hline Negative & 43 & 0.5 & 1.00 & \\
\hline \multicolumn{5}{|c|}{$\chi^{2}=14.6(p=0.000)$} \\
\hline
\end{tabular}

Table 5. Estimation of the risk to have rhinitis depending on the presence of atopy.

\begin{tabular}{|c|c|c|c|c|}
\hline Variables & With Rhinitis $^{1}$ & Without Rhinitis $^{2}$ & $\mathbf{O R}^{3}$ & $95 \% \mathrm{CI}^{4}$ \\
\hline \multicolumn{5}{|c|}{ Atopy (in all subjects) } \\
\hline Positive & 222 & 14 & 7.23 & \multirow[t]{2}{*}{$3.81-13.73$} \\
\hline Negative & 103 & 47 & 1.00 & \\
\hline \multicolumn{5}{|c|}{$\chi^{2}=44.5(\mathrm{p}=0.000)$} \\
\hline \multicolumn{5}{|c|}{ Atopy (in men) } \\
\hline Positive & 108 & 5 & 6.10 & \multirow[t]{2}{*}{$2.06-18.11$} \\
\hline Negative & 46 & 13 & 1.00 & \\
\hline \multicolumn{5}{|c|}{$\chi^{2}=11.0(p=0.000)$} \\
\hline \multicolumn{5}{|c|}{ Atopy (in women) } \\
\hline Positive & 114 & 9 & 7.55 & \multirow[t]{2}{*}{$3.39-16.82$} \\
\hline Negative & 57 & 34 & 1.00 & \\
\hline \multicolumn{5}{|c|}{$\chi^{2}=29.4(p=0.000)$} \\
\hline
\end{tabular}


Furtehrmore, the attempt to estimate atopy as a risk factor for developing asthma alone, or coincidence of asthma and rhinitis, showed that there was a significant diference in having asthma, and the combination of asthma and rhinitis together, related to the presence of atopy. Subjects with positive atopy had a greater risk of coexistence of asthma and rhinitis $\left(\chi^{2}=23.43, \mathrm{df}=1, \mathrm{p}=0.000001\right)$. The statistical analysis of separate types of allergy (seasonal, perenial and combined) are shown in Tables 6-6a.

Similar analysis of the risk of developing rhinitis depending on the presence of sensitisation to the tested groups of allergens showed that seasonal, perennial and combined allergy are associated to a significantly greater risk for developing rhinitis (Table 7).

All of the patients with isolated symptoms of rhinitis, who, at the time of evaluation had no asthma symptoms, underwent bronchoprovocation test with metacholine (BHR). An attempt was made to determine whether the presence of atopy plays a role in the risk of developing positive BHR in the subgroup of patients with rhinitis-only. The results shown in Tables 8-11 determine that the presence of atopy (especially perennial and combined sensitisation) increases the risk to have positive BHR in rhinitis-only patients- (OR 2,$33 ; 3.33 ; 3.75$ respectfully) but this difference does not reach statistical significance ( $\mathrm{P}>0.05$ in all calculations).

The subgroup of patients who had only rhinitis symptoms at initial diagnosis and positive BHR, was followed every 6 months, from the moment of first diagnosis, during, and 1 year after the end of the study, for eventual incidence of clinical features of asthma. Out of 12 male subjects with positive BHR, 2 developed asthma symptoms; one 25, and the other 39 month after initial diagnosis. Two out of 7 females with positive BHR, developed clinically manifest asthma, 23 and 36 months after initial diagnosis, respectfully. Three of them had sensitization to both seasonal and perennial allergens, and one to perennial allergens alone. There was no statistical difference in the PD20 of metacholine between these 4 subjects and the rhinitis only, BHR positive patients who had not yet developed asthma symptoms.

Routine follow up of patients with only rhinitis and negative BHR, showed that two male patients also developed asthma symptoms 28 and 34 months after the metacholine testing. In both subjects allergy to perennial allergens was detected.

Table 6. Determination of atopy as a risk factor for asthma versus asthma and rhinitis.

Pearson Chi-square: $23,4330, \mathrm{df}=1, \mathrm{p}=, 000001$

Summary Table: Expected Frequencies (Atopy_A+R.sta) Marked cells have counts $>10$ Pearson Chi-square: 23,4330, df=1, p=,000001

\begin{tabular}{|c|c|c|c|}
\hline Atopy_0_1 & Asthma & Asthma+Rhinitis & Row \\
\hline \hline 0 & 30,28214 & 108,7179 & 139,0000 \\
\hline 1 & 30,71786 & 110,2821 & 141,0000 \\
\hline All Grps & 61,00000 & 219,0000 & 280,0000 \\
\hline
\end{tabular}

Table 6a. A+R related to A, for subjects with seasonal, perennial and combined allergy.

Summary Table: Expected Frequencies (Atopy_A+R.sta) Marked cells have counts $>10$ Pearson Chi-square: 12,1623, df=1, p=,000488

\begin{tabular}{|c|c|c|c|}
\hline Atopy & Asthma & Asthma+Rhinitis & Row \\
\hline \hline 0 & 37,02010 & 101,9799 & 139,0000 \\
\hline 1 & 15,97990 & 44,0201 & 60,0000 \\
\hline All Grps & 53,00000 & 146,0000 & 199,0000 \\
\hline
\end{tabular}

Summary Table: Expected Frequencies (Atopy_A+R.sta) Marked cells have counts $>10$ Pearson Chi-square: 7,98002, df=1, p=,004731

\begin{tabular}{|c|c|c|c|}
\hline Atopy & Asthma & Asthma+Rhinitis & Row \\
\hline \hline 0 & 39,39572 & 99,6043 & 139,0000 \\
\hline 2 & 13,60428 & 34,3957 & 48,0000 \\
\hline All Grps & 53,00000 & 134,0000 & 187,0000 \\
\hline
\end{tabular}

Summary Table: Expected Frequencies (Atopy_A+R.sta) Marked cells have counts $>10$ Pearson Chi-square: 10,0822, df=1, p=,001498

\begin{tabular}{|c|c|c|c|}
\hline Atopy & Asthma & Asthma+Rhinitis & Row \\
\hline \hline 0 & 39,59884 & 99,4012 & 139,0000 \\
\hline 3 & 9,40116 & 23,5988 & 33,0000 \\
\hline All Grps & 49,00000 & 123,0000 & 172,0000 \\
\hline
\end{tabular}


Table 7. Determination of the risk of development of rhinitis according to the presence of seasonal, perennial and sensitisation to both groups of allergens (seasonal and perennial allergy together).

\begin{tabular}{|c|c|c|c|}
\hline Atopy & Rhinitis (Positive) & Rhinitis (Negative) & OR - Odds ratio \\
\hline Positive & 103 & 6 & 7.8 \\
\hline \multicolumn{4}{|c|}{$\chi^{2}=25.87 \mathrm{p}<0.05 ; 95 \%$ Confidence interval $(3.2<\mathrm{OR}<19.1)$} \\
\hline Atopy (Perennial) & Rhinitis (Positive) & Rhinitis (negaTive) & OR - Odds Ratio \\
\hline Negative & 103 & 47 & 1.00 \\
\hline \multicolumn{4}{|c|}{$\chi^{2}=14.16 \mathrm{p}<0.05 ; 95 \%$ Confidence interval $(2.03<\mathrm{OR}<12.39)$} \\
\hline Atopy (Seasonal and Perennial) & Rhinitis (Positive) & Rhinitis (Negative) & OR - Odds Ratio \\
\hline
\end{tabular}

Table 8. Determination of the risk of development positive BHR in rhinitis-only patients, according to the presence of atopy in general.

\begin{tabular}{|c|c|c|c|}
\hline Atopy & BHR-Positive & BHR-Negative & OR - Odds Ratio \\
\hline \hline Positive & 18 & 77 & 2.33 \\
\hline Negative & 1 & 10 & 1.00 \\
\hline
\end{tabular}

Table 9. Determination of the risk of development of positive BHR in rhinitis-only patients, according to the presence of sensitization to seasonal allergens.

\begin{tabular}{|c|c|c|c|}
\hline $\begin{array}{c}\text { Atopy } \\
\text { (Seasonal) }\end{array}$ & BHR-Positive & BHR-Negative & OR - Odds Ratio \\
\hline \hline Positive & 6 & 43 & 1.39 \\
\hline Negative & 1 & 10 & 1.00 \\
\hline
\end{tabular}

Table 10. Determination of the risk of development of positive BHR in rhinitis-only patients, according to the presence of perennial allergy.

\begin{tabular}{|c|c|c|c|}
\hline $\begin{array}{c}\text { Atopy } \\
\text { (Perennial) }\end{array}$ & BHR-Positive & BHR-Negative & OR - Odds Ratio \\
\hline \hline Positive & 6 & 18 & 3.33 \\
\hline Negative & 1 & 10 & 1.00 \\
\hline \multicolumn{2}{|c|}{$\chi^{2}=0.40(p=0.523) p>0.05 ; 95 \%$ Confidence interval $(0.35<$ OR $<31.74)}$.
\end{tabular}

\section{DISCUSSION}

The primary outcome of our study was to determine the joint incidence of asthma and rhinitis in our population. The
Table 11. Determination of the risk of development of positive BHR in rhinitis-only patients, according to the presence of combination of seasonal and perennial allergy.

\begin{tabular}{|c|c|c|c|}
\hline $\begin{array}{c}\text { Atopy ( } \\
\text { Seasonal } \\
\text { and Perennial) }\end{array}$ & BHR-Positive & BHR-Negative & OR - Odds Ratio \\
\hline \hline Positive & 6 & 16 & 3.75 \\
\hline Negative & 1 & 10 & 1.00 \\
\hline
\end{tabular}

group of patients evaluated in this study is heterogeneous and the patients were not recruited only from the narrow region of Skopje. According to the knowledge of the authors, there is only one major study treating the incidence of asthma and rhinitis in Macedonia, done by the Institute of occupational medicine in Skopje- Collaborative Center of WHO, in which the prevalence of asthma is $5.4 \%$ of the population, atopy is present in $34,8 \%$, and the prevalence of chronic rhinitis is 30.2\% (23.1\% allergic rhinitis; $16,5 \%$ seasonal AR and $6.7 \%$ perennial allergic rhinitis) [11]. The drawback of this study is that the results were based on selfreported diagnosis, later-on confirmed by testing for atopy and asthma. In our study, atopy was detected in $61 \%$ of the subjects (28.2\% seasonal, 18,6\% perennial and 14,2\% both). On the other hand, analyzing the subgroup of asthma-only patients who did not present with rhinitis symptoms showed that atopy was present in only $21.4 \%$. In the subgroup of all of the patients with asthma, atopy was detected in $50.4 \%$, with no gender differences. The univariant analysis confirmed atopy as a independent risk factor for asthma, as well as for rhinitis, and for the coexistence of asthma and rhinitis. A strong association of atopy and asthma and rhinitis has been found in numerous studies [12]. Seasonal allergens are usually associated to allergic rhinitis, and indoor allergens to asthma, but recent studies show that more 
than $50 \%$ of patients with seasonal allergy suffer from perennial rhinitis and in general population, a large number of subjects sensitized to mites have mild intermittent allergic rhinitis [13].

Asthma and rhinitis have common pathogenetic mechanisms as well as epidemiologic features, and an integrated approach is essential [14-16]. Various mechanisms have been reported, including the mutual microbiome and its immunomodulatory capacities influencing asthma and perhaps chronic rhinitis [17]. The joint incidence of asthma and rhinitis has been reported in many studies, and numbers as high as $75-95 \%$ of asthmatics having rhinitis are common $[18,19]$. Same findings apply to occupational circumstances as well, leading to a revision of the guidelines [20]. In recent studies rhinitis symptoms were found in $98.9 \%$ of asthmatics [21], and $20-38 \%$ of patients with allergic rhinitis have concomitant asthma. Furthermore, allergic rhinitis is considered an independent risk factor for developing asthma [22], but nowadays it is not clear whether rhinitis precedes asthma, or this condition merely represents an early stage of united airway disease, which in time, progresses to full manifestation of asthma. We tried to shed some light to this question by testing the BHR in the rhinitis-only patients, expecting to determine the presence of positive airway hyperresponsiveness in patients with no evident asthma symptoms at the time of evaluation. We found that $18 \%$ of these patients had positive hyperresponsiveness, meaning that almost 1 out of 5 subjects are prone to developing, or better more, had developed asthma, although they initially did not meet GINA criteria for diagnosis. Subclinical changes in the lower airways are described and inflammatory mediators have been detected even in patients who do not have asthma [23], and it is well established that treatment of rhinitis may have a positive effect on the clinical presentation and control of asthma [24]. Similar results are reported in numerous studied leading to the recommendations in the 2008 updated ARIA guidelines that "allergic rhinitis (AR) is a risk factor for asthma, and patients with persistent rhinitis should be evaluated for asthma" [13]. Evaluation of atopy as a risk factor for positive BHR in patients with rhinitis in our study, showed that the presence of atopy (especially perennial and combined sensitisation) increases the risk to have positive BHR in rhinitis-only patients (OR 2,33; 3.33; 3.75 respectfully) but this difference does not reach statistical significance ( $\mathrm{P}>0.05$ in all calculations). Ricconi et al. have reported that perennial atopy (or rhinitis) is associated with greater BHR than seasonal atopy [25], but such an association was not confirmed in our study.

The follow up of the patients enrolled in this study went on during the whole recruitment period, and one year after, with special regards to the patients only with rhinitis with and without airway hyperresponsiveness. There was no association to specific type of atopy nor statistical difference in the PD20 for metacholine between these 4 subjects and the rhinitis only, BHR positive patients who had not yet developed asthma symptoms.. Still, we conclude that the number of patients who developed asthma symptoms during the follow up period in our study was too small for conclusive statistical analysis.
New onset of asthma in patients previously diagnosed with rhinitis, with an incidence up to $2.2 \%$ has been described in several longitudinal studies [26-29] and rhinitis has been reported to arise with time, in patients who presented only with asthma symptoms, and these data even strongly confirm the concept of the "United airways" and the theory that asthma and rhinitis are actually one single disease, with variations of appearance of symptoms in time, and "the key to managing both disorders is prevention and relief of chronic allergic inflammation in both the upper and lower airways" [30].

\section{CONFLICT OF INTEREST}

The authors confirm that this article content has no conflict of interest.

\section{ACKNOWLEDGEMENTS}

\author{
Declared none.
}

\section{REFERENCES}

[1] Bonini S, Denburg J. The role of shock organs in influencing the clinical expression of allergy. Allergy 1999; 54: 3-6.

[2] Bousquet J. Allergy as a global problem: "Think globally, act globally". Allergy 2002; 57: 661-2.

[3] Bonini S. ARIA and GAP extending still further. Summer School'02, Sofia. Bulgaria.

[4] Bousquet J, Van Cauwenberge P, Khaltaev N. Allergic rhinitis and its impact on asthma. J Allergy Clin Immunol 2001; 108: S198S201.

[5] The International Study of Asthma and Allergies in Childhood (ISAAC) Steering Committee. Worldwide variation in prevalence of symptoms of asthma, allergic rhinoconjunctivitis, and atopic eczema: ISAAC. Lancet 1998; 351: 1225-32.

[6] Leynaert B, Neukirch C, Kony S, et al. Association between asthma and rhinitis according to atopic sensitization in a population-based study. J Allergy Clin Immunol 2004; 113: 86-93.

[7] ARIA workshop Group. Allergic Rhinitis and Its impact on Asthma. JACI 2001; 108: 5.

[8] Bousquet J, Khaltaev N, Cruz A, et al. ARIA Update. Allergy 2008; 63(suppl).

[9] Johnstone D, Dutton A. The value of hyposensitization therapy for bronchial asthma in children: a 14 year study. Pediatr 1968; 42: 793-4.

[10] Gjorcev A. Macedonian national plan and programme for diagnosis and treatment of asthma - reality or vision. Skopje: Biro M\&M 1996.

[11] Cvetanov V. Allergic diseases in R. Macedonia. Skopje 2006; 115139: $151-72$

[12] Garden FL, Simpson JM, Marks GB; CAPS Investigators. Atopy phenotypes in the Childhood Asthma Prevention Study (CAPS) cohort and the relationship with allergic disease: clinical mechanisms in allergic disease. Clin Exp Allergy 2013; 43(6): 63341.

[13] Bauhau V, Durham SR. Prevalence and rate of diagnosis of allergic rhinitis in Europe. Eur Respir J 2004; 24(5): 758-64.

[14] Bosquet J. MeDALL (Mechanisms of the Development of Allergy): an integrated approach from phenotypes to systems medicine. Allergy 2011; 66(5): 596-604.

[15] Cruz AA, Popov T, Pawankar R, et al. Common characteristics of upper and lower airways in rhinitis and asthma: ARIA update, in collaboration with GA(2)LEN. Allergy 2007; 62(Suppl 84): 1-41.

[16] Jarvis D, Newson R, Lotvall J, et al. Asthma in adults and its association with chronic rhinosinusitis: the GA2LEN survey in Europe. Allergy 2012; 67(1): 91-8.

[17] Suzaki H, Watanabe S, Pawankar R. Rhinosinusitis and asthmamicrobiome and new perspectives. Curr Opin Allergy Clin Immunol 2013; 13(1): 45-9 
[18] Annesi-Maesano I. Epidemiological evidence of the occurrence of rhinitis and sinusitis in asthmatics. Allergy 1999; 54(Suppl): 7-13.

[19] Kapsali T, Horowitz E, Togias A. Rhinitis is ubiquitous in allergic asthmatics. J Allergy Clin Immunol 1999; 99: S138.

[20] Ameille J, Hamelin K, Andujar P, et al. Occupational asthma and occupational rhinitis: the united airways disease model revisited. Occup Environ Med 2013; 70(7): 471-5.

[21] Simons FER. Allergic rhinobronchitis: the asthma-allergic rhinitis link. J Allergy Clin Immunol 1994; 104: 534-40.

[22] Moller C, Dreborg S, Ferdousi HA, et al. Pollen immunotherapy reduces the development of asthma in children with seasonal rhinoconjunctivitis (the PAT study). J Allergy Clin Immunol 2002; 109: 251-6.

[23] Compalati E, Riodlo E, Passalacqua G, et al. The link between allergic rhinitis and asthma: the united airways disease. Expert Rev Clin Immunol 2010; 6(3): 413-23

[24] Lohia S, Schlosser RJ, Soler ZM. Impact of intranasal corticosteroids on asthma outcomes in allergic rhinitis: a metaanalysis. Allergy 2013; 68(5): 569-79
[25] Riccioni G, Della Vecchia R, et al. Bronchial hyperresponsivenes in adults with seasonal and perenial rhinitis: is there a link for asthma and rhinitis? Int J Immunopathol Pharmacol 2002; 15(1): 69-74.

[26] Settipane G, Settipane RJ, Hagy GW. Long term risk factors for developing asthma amd allergic rhinitis: a 23 year follow up study of college students. Allergy Proc1994; 15: 21-25.

[27] Anderson HR, Pottier AC, Strachan DP. Asthma from birth to age 23: incidence and relationship to prior and concurrent atopic status. Thorax 1992; 47: 537-42.

[28] Burgess JA, Walters EH, Byrnes GB et al. Childhood allergic rhinitis predicts asthma incidence and persistence to middle age: a longitudinal study. J Allergy Clin Immunol 2007; 120(4): 863-69.

[29] Shaaban R, Zureik M, Soussan D, et al. Rhinitis and onset of asthma: a longitudinal population based study. Lancet 2008; 372: 1049-57.

[30] Simons FE. Allergic rhinobronchitis: the asthma-allergic rhinitis link. J Allergy Clin Immunol 1999; 104(3 Pt 1): 534-40.

(C) Zdraveska et al.; Licensee Bentham Open.

This is an open access article licensed under the terms of the Creative Commons Attribution Non-Commercial License (http://creativecommons.org/licenses/by-nc/3.0/) which permits unrestricted, non-commercial use, distribution and reproduction in any medium, provided the work is properly cited. 